\title{
Greater involvement of PLHA In NGO service delivery: Findings from a four-country study
}

Horizons Program

Follow this and additional works at: https://knowledgecommons.popcouncil.org/departments_sbsr-hiv

Part of the Health Services Research Commons, and the International Public Health Commons How does access to this work benefit you? Let us know!

\section{Recommended Citation}

"Greater involvement of PLHA In NGO service delivery: Findings from a four-country study," Horizons Research Summary. Washington, DC: Population Council, 2002. 


\section{Hqrizons $\Lambda$}

\section{Greater InVolvement of PLHA in NGO Service DeLIVERY:}

FINDINGS FROM A FOUR-COUNTRY STUDY

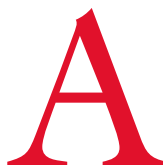

t the conclusion of the Paris AIDS Summit in 1994, 42 governments issued a declaration supporting greater involvement of people living with HIV/AIDS (PLHA) in policy formulation and service delivery. Despite growing recognition of its importance, there has been little research that examines PLHA involvement in the delivery of prevention, care, and support services in developing countries and its effects on PLHA, others affected by HIV/AIDS, and nongovernmental organizations (NGOs).

To address this gap, the Horizons Program and the International HIV/AIDS Alliance conducted a study of PLHA involvement in NGOs in Burkina Faso, Ecuador, Zambia and Maharashtra State, India, between October 1998 and August 2001. The goal of the study was to identify the conditions that foster PLHA involvement

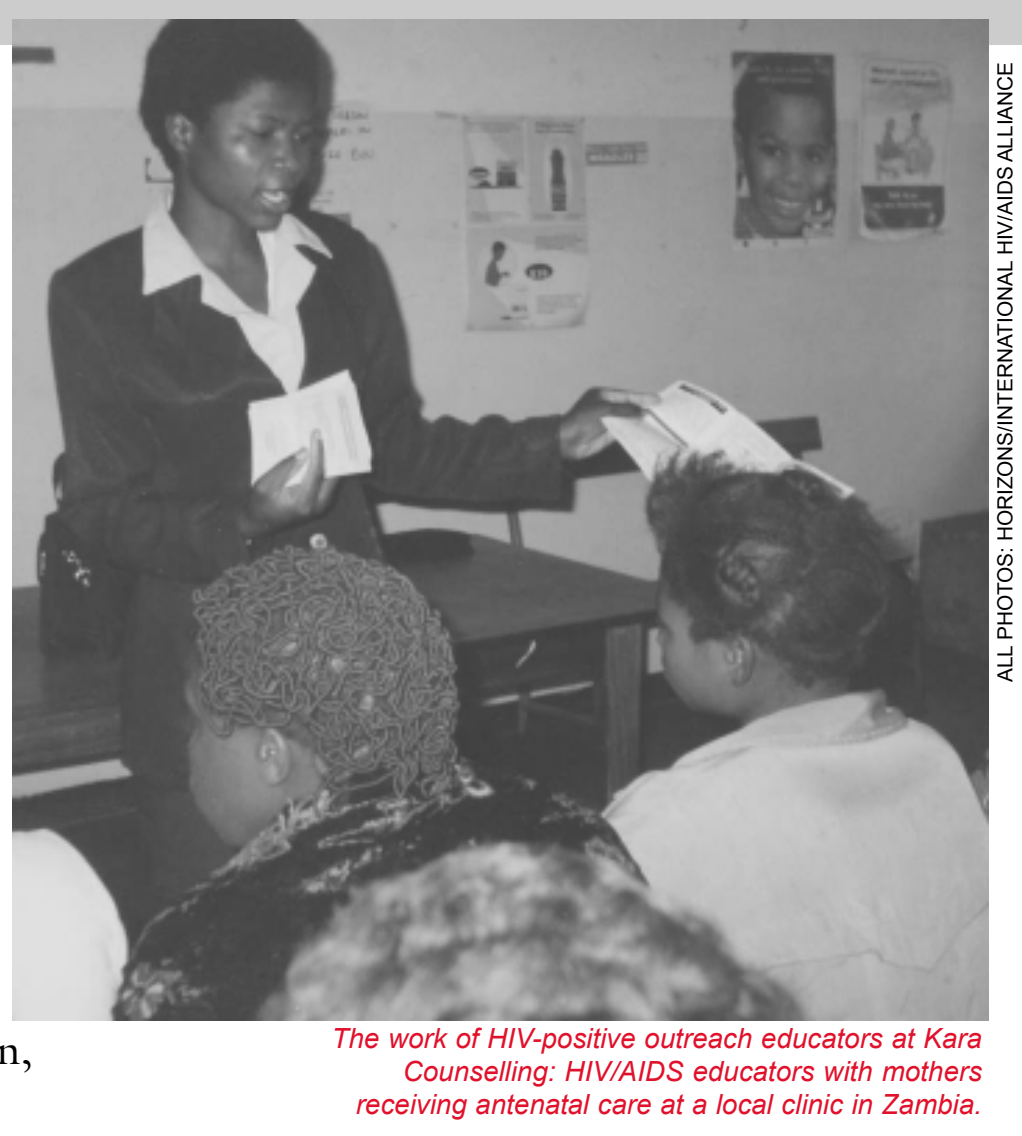

and the strategies that organizations can use to achieve meaningful involvement of PLHA.

Seventeen NGOs participated in the study, all of which focus on HIV/AIDS prevention, care, and support. The NGOs chosen represent different types of organizations and a range of PLHA involvement, and all expressed interest in the aims of the study. 


\section{Participating NGOs}

- Burkina Faso: Association African Solidarité (AAS); Association Laafi la Viim (ALAVI); Appui Moral Matériel et Intellectuel à l'Enfant (AMMIE); La Bergerie-Foi, Univers, Compassion; Association Responsabilité Espoir Vie Solidarité + (REVS+)

- Ecuador: Fundación Dios, Vida y Esperanza; Fundación Esperanza; Fundación Siempre Vida; Fundación Vivir

- Maharashtra State, India: Project CHILD of Committed Communities Development Trust (CCDT); Maharashtra Network for Positive People (MNP+); Salvation Army Mumbai HIV/AIDS Community Development Program; Society of Friends of Sassoon Hospitals (SOFOSH)

- Zambia: Copperbelt Health Education Project (CHEP); Hope Humana People to People; Kara Counselling and Training Trust; Salvation Army Chikankata Mission Hospital

\section{Study Methods}

Researchers from each of the four countries collected data via qualitative and quantitative methods, including individual and group interviews, focus group discussions, observation, service statistics, and a questionnaire. The study recruited 745 individuals, including HIV-negative and -positive service users, NGO staff, and volunteers, and such key informants as policymakers, health professionals, and community leaders. In all four countries, PLHA were involved in the participating NGOs as service providers, service users, or both.

PLHA represented about half of study participants in India and Zambia, 35 percent in Ecuador, and 15 percent in Burkina Faso. Table 1 summarizes the number of participating NGOs and research sites and the type and number of respondents per country.

The research teams used a participatory approach throughout the study. The NGOs in each country were actively involved in study design, implementation, and validation and interpretation of the findings. An orientation workshop held at the start of the study in each country familiarized the NGOs with basic research concepts; discussed the study rationale, relevance, and process; and adapted the methodology and tools to the national context. The teams also conducted a data analysis and interpretation workshop with the participating NGOs in each country to discuss the findings and to identify strategies to increase PLHA involvement.

\section{Identifying the Types of PLHA Involvement}

The research teams used the following criteria to examine how PLHA are involved in NGOs.

- Time spent on and regularity of activities.

- Remuneration: financial (salary, allowance, reimbursement of travel costs), material (food, medicines), technical (training), or psychological (social support and counseling).

- Skills used.

- Skills development provided by the organization.

- Scope and autonomy of decision making.

- Level of visibility: internal (within the NGO) and external (outside the NGO). 
Table 1 Characteristics of study sites and populations

\begin{tabular}{|c|c|c|c|c|c|c|}
\hline \multirow[b]{2}{*}{ Country } & \multirow[b]{2}{*}{$\begin{array}{l}\text { Number } \\
\text { of NGOs }\end{array}$} & \multirow[b]{2}{*}{$\begin{array}{l}\text { Study } \\
\text { sites }\end{array}$} & \multicolumn{4}{|c|}{ Respondents } \\
\hline & & & $\begin{array}{c}\text { Service } \\
\text { providers } \\
\text { (staff or } \\
\text { volunteers) }\end{array}$ & $\begin{array}{c}\text { Service } \\
\text { users }\end{array}$ & $\begin{array}{c}\text { Relatives } \\
\text { of PLHA } \\
\text { providers }\end{array}$ & $\begin{array}{c}\text { Key } \\
\text { informants }\end{array}$ \\
\hline Burkina Faso & 5 & $\begin{array}{l}1 \text { urban and } \\
\text { semi-rural } \\
4 \text { urban }\end{array}$ & 103 & 19 & 5 & 49 \\
\hline Ecuador & 4 & 4 urban & *115 & & 5 & 52 \\
\hline India & 4 & $\begin{array}{l}1 \text { urban and } \\
\text { semi-rural } \\
3 \text { urban }\end{array}$ & 48 & 82 & 2 & 10 \\
\hline Zambia & 4 & $\begin{array}{l}1 \text { rural } \\
1 \text { urban and } \\
\text { semi-rural } \\
2 \text { urban }\end{array}$ & 101 & 115 & 7 & 34 \\
\hline
\end{tabular}

* In Ecuador, the researchers did not distinguish between service providers and service users, because many HIV-positive service providers are also service users.

\section{Country Context}

Estimates of HIV prevalence in the general population vary considerably among the four countries (Ecuador, less than 1 percent; Burkina Faso, 6.5 percent; Zambia, 20 percent). In Maharashtra State, India, almost 2 percent of women attending antenatal services are infected, a figure suggesting the extent of the spread in the general population. In the two African countries, transmission is mainly heterosexual, whereas in Ecuador, homosexual and bisexual transmission account for about a third of AIDS cases.

Transmission is also predominantly heterosexual in India, but there are important sub-epidemics among men who have sex with men (MSM) and injecting drug users. More than half of PLHA in Burkina Faso and Zambia are women, compared with about 35 percent in Ecuador and India.

PLHA are highly stigmatized in all four countries because of the association of HIV/AIDS with certain behaviors and population groups. Fear of stigma and discrimination means that few individuals are willing to divulge their HIV status or find out their status through HIV testing. In Burkina Faso, India, and Zambia, voluntary counseling and testing (VCT) services are not widely available, and access to antiretrovirals (ARVs) is limited to PLHA with money or international contacts. In Ecuador, ARVs are available to those eligible to use police and military hospitals and in one region to those with access to social security. Access to non-ARV treatment and care is particularly poor in Burkina Faso, India, and rural Zambia.

There are national networks of PLHA in Ecuador, India, and Zambia, but visible involvement of PLHA is low in all four countries. The organization of PLHA started in the late 1980s and early 1990s in Ecuador and Zambia, but is a relatively recent phenomenon in Burkina Faso and India. In all four countries the main impetus for greater PLHA involvement has come from international donors, NGOs, and activists, which have supported the development of PLHA organizations and networks and encouraged governments to give higher priority to PLHA involvement in the response to the epidemic. 


\section{Key Findings}

\section{There are four distinct types of PLHA involvement.}

Access to services for PLHA involves taking part in NGO activities as beneficiaries or users of services, such as medical care, counseling, or training. Access was the most common type of PLHA involvement observed among the 17 NGOs participating in the study. At this first stage, PLHA learn not only about HIV/AIDS but how to accept their HIV status and cope with infection, which can help motivate them to help others.

I felt so alone. I thought I was going to die there and then...the group...has been a great psychological support... I haven't been to a psychologist but I have been helped by seeing a group of people in the same situation; this has helped my self-esteem.

HIV-positive member, Fundación Siempre Vida, Ecuador

Examples of services that aim to empower PLHA and thus foster further involvement in NGO activities include:

- Positive living and life skills courses help

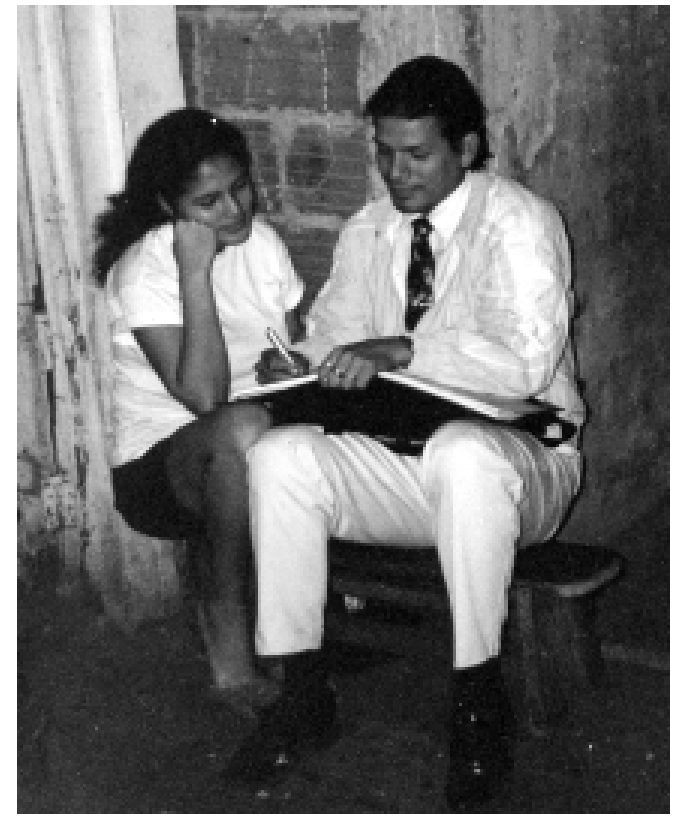

A member of Siempre Vida Foundation providing peer support, Guayaquil, Ecuador.
PLHA come to terms with their HIV status and provide information and skills to gain control over their lives.

- Support groups provide an opportunity to share problems, offer mutual support, and furnish a safe space for PLHA to become visible. Support groups can empower PLHA by building their self-esteem and preparing them to be open about their HIV status.

- Counseling helps PLHA accept their HIV status and prepare for possible repercussions of visibility. Counselors can refer PLHA to other activities and to training to develop their capacity for further involvement.

During the counseling...they discover their personal value in society and the community where they come from. The things they learn during counseling, education they acquire, and their own life experiences tend to make them come out in the open to help the community.

Service provider, Kara Counselling and Training Trust, Zambia

Inclusion is when NGOs involve PLHA as support staff and volunteers in non-HIV/AIDS activities or as occasional volunteers in HIV/ AIDS service delivery (e.g., providing informal peer support at support group meetings, conducting home and hospital visits or community outreach activities). Formal training at this stage is limited. Important incentives for PLHA include greater access to peer support and interaction with other PLHA. However, there are few material rewards for their efforts. Use of PLHA as volunteers may be cost-effective for NGOs but can have an adverse effect on service quality if volunteers are poorly trained.

Participation is when PLHA deliver HIV/AIDSrelated services on a formal, regular basis, as employees or volunteers. Their expertise is recognized by the organization and they generally receive financial remuneration for their work, although in Burkina Faso and Ecuador many regular volunteers do not receive any financial remuneration. These PLHA may be involved in planning the services they deliver and, in some 


\section{PLHA Mobilization and Involvement}

The data reveal that PLHA become mobilized in different ways:

- In five NGOs, PLHA set up organizations, often together with other affected people or health and social workers. These NGOs are rights-based organizations and/or self-help groups. The dominant models are greater involvement and participation, but there are also PLHA who use services. These organizations can evolve depending on the composition of the membership. In two NGOs, the HIV-positive founders died and the organizations became more service-oriented and less focused on rights.

In NGOs where there were originally no visible PLHA, such as secular or religious welfare organizations and development NGOs:

- NGOs empower their HIV-positive service users to become service providers through inclusion and sometimes participation, as was the case with six NGOs. This rarely leads to greater involvement, unless there is a clear policy within the organization, as in the case of one NGO in Zambia.

- Organizations recruit PLHA who are not their service users and who are already visible and have the experience and skills to be involved in formal service delivery and/or management (participation and greater involvement). This scenario was observed in one development NGO in Zambia.

- Sometimes NGO staff or volunteers find out that they are HIV-positive and choose to become visible. However, this only occurred in one organization in Burkina Faso.

organizations, are consulted about other services. At this level of involvement, PLHA have accepted their status and use their experience living with HIV/AIDS plus skills and theoretical knowledge gained in formal training to deliver services.

Greater involvement is the most advanced stage of involvement, where PLHA take part in management, policymaking, and strategic planning as directors, trustees, or program managers and may represent the organization externally. This type of involvement implies a higher level of visibility that can expose PLHA to the risk of stigma and discrimination, although these PLHA are likely to be better able to cope because they generally have high levels of personal acceptance and support.

PLHA involvement in management and decision-making occurs in the rights-based organizations, such as PLHA groups and networks. With one exception, PLHA who participate in management, policymaking, and strategic planning completed at least secondary education and are from middle-income socioeconomic groups. Most have been involved in the fight against the epidemic for many years and have had considerable training. Examples of this type of involvement include the following:

- At MNP+ in India and REVS+ in Burkina Faso, PLHA manage the organization and specific programs, and at CHEP in Zambia, the coordinator and assistant of the PLHA program are both HIV-positive.

- At MNP+ and REVS+, PLHA were volunteer members of the board of trustees. At CHEP and Kara Counselling and Training Trust in Zambia, PLHA program coordinators are involved in organizational strategic planning.

- PLHA who manage organizations and programs often have a significant representative role outside the NGO with which they are involved, expressing the perspectives of PLHA in different forums, and many participate in advocacy efforts in national and regional networks of PLHA. 


\section{Involvement in NGO activities can have therapeutic effects for PLHA.}

Although the impact of involvement on PLHA depends on the way they are involved in NGOs, study respondents overall reported a therapeutic effect of involvement for PLHA. This includes improved psychological health as a result of increased peer support and knowledge, and decreased isolation; improved physical health due to access to information about care, including where and how to access it, and in some cases, medical care and treatment; and increased income or access to material benefits as compensation for services. Some respondents in Zambia and Ecuador also cited less risky behavior, especially reductions in the number of sexual partners, and better integration in the family as members realize that PLHA can be productive and inform others in the family about HIV/AIDS.

The family wish that I help the young ones...so the family is very happy for me coming out in the open.

HIV-positive service provider, CHEP, Zambia
They know me at the hospital and the doors are always open for me. I get there and make sure they attend my patients.

HIV-positive counselor, Siempre Vida, Ecuador

The group has really boosted my morale... when we meet as a group we feel better because the way we relate to each other is like one big family. You become a pillar of strength for those who have just been tested.

PLHA self-help group participant,

CHEP, Zambia

The benefit of associating with the agency is that today I know so much. If I had sat at home I wouldn't have known so many things.

PLHA service provider, $\mathrm{MNP}+$, India

Nonetheless, respondents in all four countries reported drawbacks to PLHA involvement, depending on the activities carried out and the level of visibility. For example, when delivering care and support services, the psychological health of asymptomatic PLHA can be impaired as a result of contact with those who are very sick. In

Members of REVS+ in Burkina Faso wear prevention messages during an HIVIAIDS awareness-raising campaign. From left to right: "I love you--I protect you," "I've been tested; have you?" and "Protect yourself--

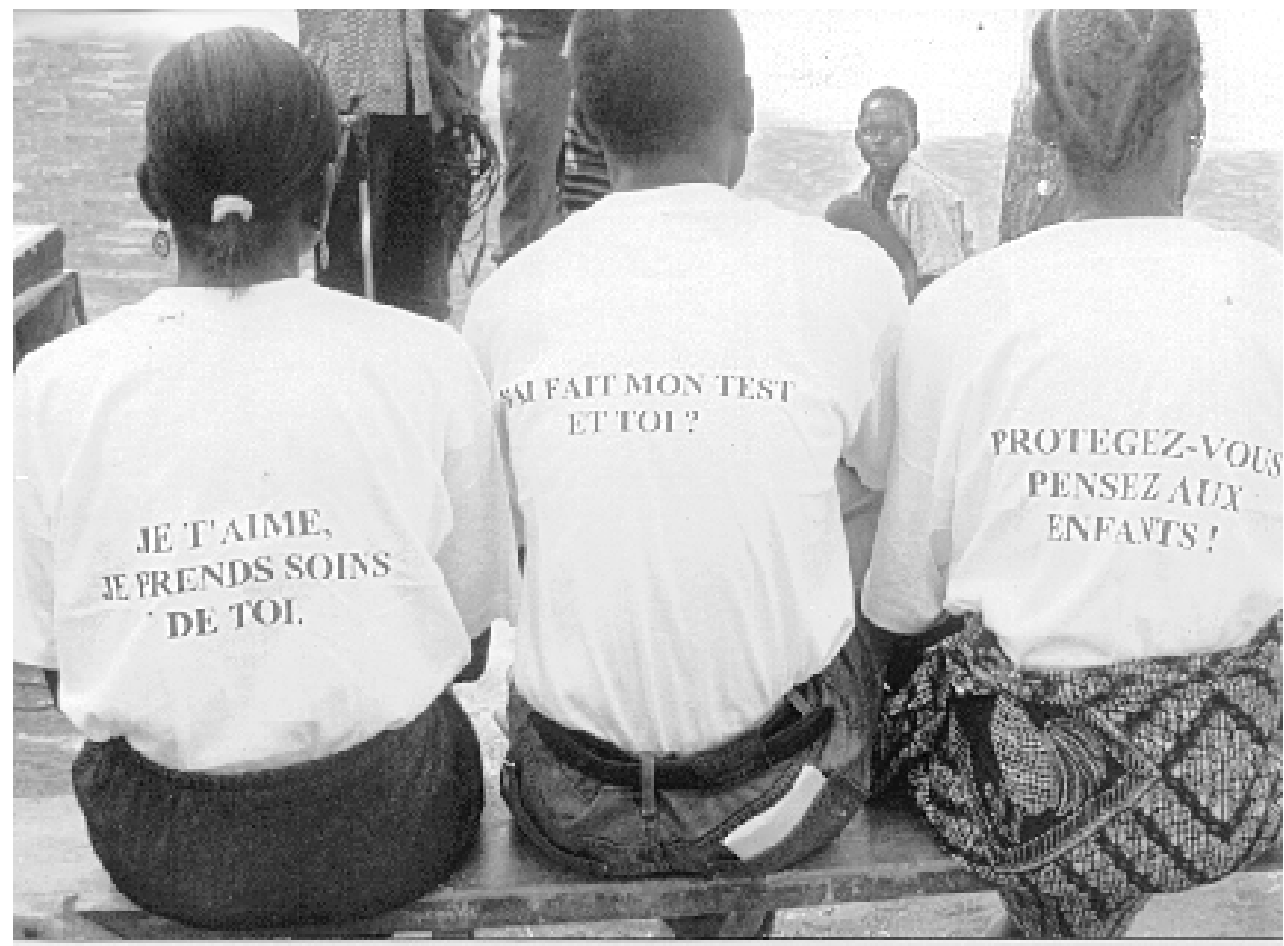


Ecuador and Zambia, some PLHA reported personal experiences of stigma and discrimination because of their visible involvement in delivering services and/or managing the NGO. A few respondents from Burkina Faso and Zambia reported that occasionally community members accuse PLHA of pretending to be HIV-positive in order to obtain money from donors. NGOs need to be conscious of potential negative effects in order to take steps to minimize them.

I have suffered a lot of discrimination since $I$ decided to come out in the open and especially since my decision to get involved. People really laughed at me. My friends stopped playing football with me...My parents-in-law succeeded in taking my wife away from me.

PLHA service provider, Salvation Army, Zambia

\section{PLHA involvement strengthens NGOs.}

Data from the study highlight that PLHA involvement in service delivery and management helps to improve services and strengthen organizations by:

- Improving care and support services by making them more relevant and personalized.

- Increasing effectiveness of prevention activities by improving people's perceptions of PLHA.

- Raising staff awareness of the issues from the PLHA perspective and promoting recognition by staff of the contributions PLHA can make.

- Increasing credibility of the organization and its services.

- Broadening activities to include advocacy for the rights of PLHA.

I came to realize that they were normal people just like any other human being. I could eat with them and share plates with them. Now I think I understand HIV much more than I did.

HIV-negative service provider, Kara Counselling and Training Trust, Zambia

Respondents also identified several detrimental effects that PLHA involvement can have on the organization. However, with adequate planning these negative repercussions can be reduced. For example, PLHA who are poorly trained may convey inaccurate information or impose their own solutions during counseling. When PLHA become ill and die, the NGO may experience disrupted service delivery and increased costs for training replacements, which may affect the sustainability of the organization itself. In some instances, visibility can lead to a kind of "stardom" for a few PLHA, which can create tensions within an organization. There is also the potential for conflict between PLHA and HIVnegative staff if the role and contribution of either are undervalued.

\section{The socioeconomic context strongly influences PLHA involvement.}

Any strategies to promote the greater involvement of PLHA in developing countries must take into account the social context, especially conditions of poverty, limited access to health care and treatment, gender inequality, and stigma and discrimination. With regard to poverty, most PLHA in the study are from low-income groups and need to use their available time to earn an income, therefore limiting their involvement on a voluntary basis. Poor health can limit involvement, although PLHA can remain involved even when they are sick, provided they are asked to do tasks that take into account their health needs and have access to treatment. PLHA, especially women and those from low-income groups, are less likely to have had access to education required for formal service delivery and program management. In some settings, illiteracy is a major barrier to involvement. Gender inequalities in access to education and services, domestic and childcare responsibilities, and financial dependence on men prevent many HIV-positive women from becoming involved in NGO activities.

If...transport is not provided, only those who are convinced come. When they know that there is some support they come. This is perhaps linked to the economic situation...there is extreme poverty, it is difficult.

Member of ALAVI, Burkina Faso 


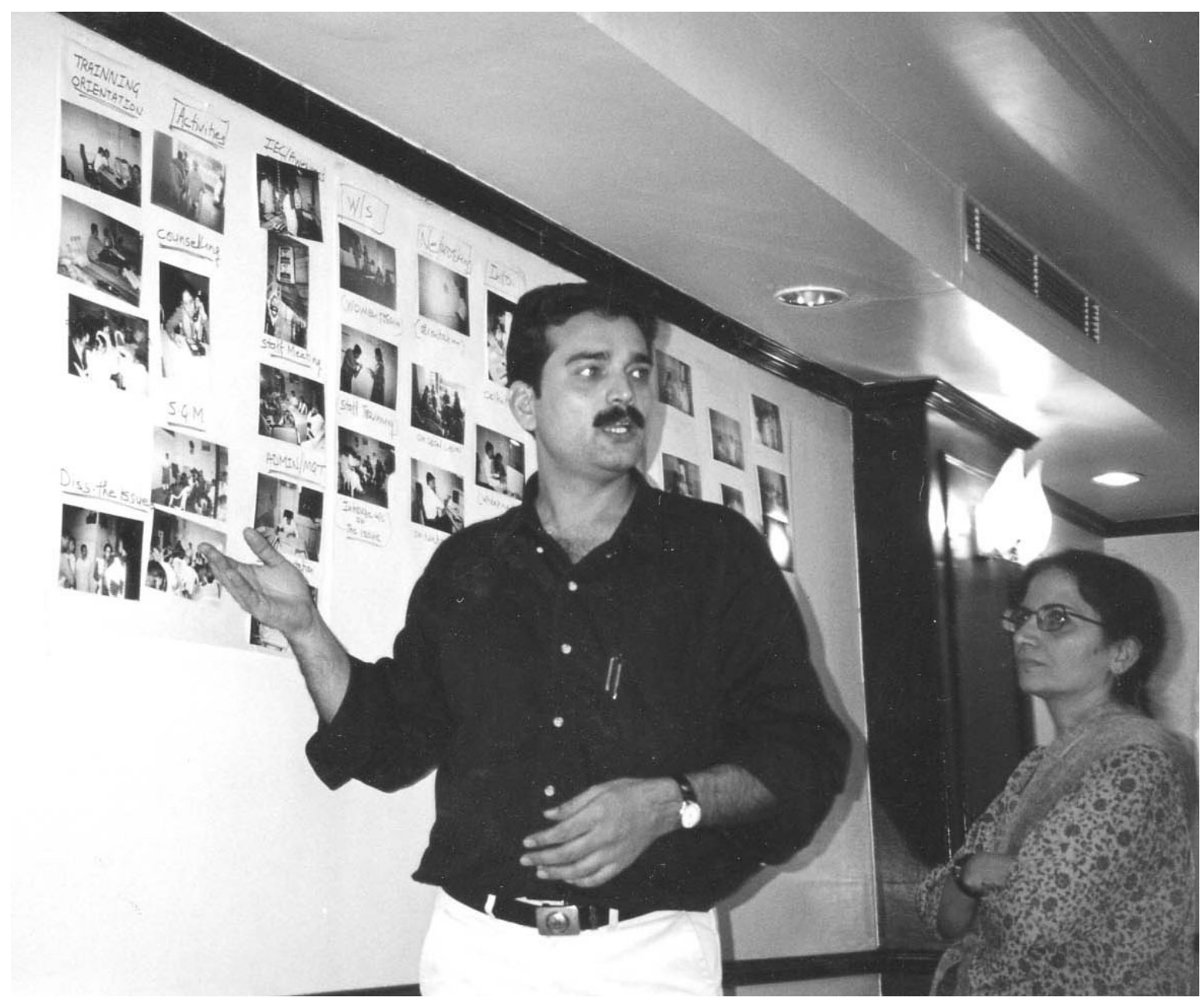

To facilitate their involvement in the research process, study participants use photographs to discuss their program's activities at a data analysis workshop in India.

We are not so educated...sometimes I speak but I feel hesitant...I do not know how to speak.

Female PLHA beneficiary, CCDT, India

Fear of stigma and discrimination inhibit many PLHA from involvement, especially in NGOs perceived to be "PLHA organizations" and in roles with high visibility. This was particularly true in Burkina Faso and India, and in rural settings where fewer PLHA are visible. Rejection by family, friends, and the community due to stigma, as well as lack of knowledge and discrimination within health service and workplace settings, reinforces fears about PLHA involvement. In Ecuador and Zambia, some PLHA informants described actual experiences of stigma and discrimination as a result of their visible involvement in NGOs.
In Africa...it isn't easy. If people say you are involved in an organization of infected people, you know that you are labeled.

PLHA, Burkina Faso

\section{PLHA involvement should not be equated with public disclosure and visibility.}

In all four countries the study documented a range of NGO activities carried out by PLHA, not all of which entail disclosure within the organization or public visibility. For example, not all PLHA disclose their status to clients they counsel or to the community while doing outreach education. However, examples of PLHA who are visibly involved in providing personal testimonies that give a "human face" to the epidemic were found in each country, although few PLHA have gone public in the media. In 
Zambia, outreach education is the activity in which PLHA are most likely to be involved. In contrast, in the other three countries, PLHA involvement in community awareness-raising activities was limited to a few individuals. Most informants noted that some degree of visible PLHA involvement within NGOs increases awareness of PLHA perspectives and needs and contributes to better services. However, the involvement of PLHA should be matched with the degree of visibility with which they feel comfortable. PLHA should not be forced to disclose their HIV status and NGOs should guarantee the confidentiality of all service providers and beneficiaries.

After seeing us, their perception toward life changes and fear goes out of them. They start feeling that they can also change and live life.

HIV-positive peer counselor, Salvation Army, India

The PLHA are afraid of NGO members finding out their serostatus. They are afraid that if this happens they will be marginalized.

Service provider, AMMIE, Burkina Faso
- Lack of institutional will and policies to create varied opportunities for PLHA to be involved.

$H I V$-positive patients are not involved in our organization because we don't have welldefined plans for them.

HIV-negative service provider, Fundación Esperanza, Ecuador

They suggested to me that I could come and help but when I came they didn't know what I could do.

HIV-positive service user, Ecuador

- Lack of attention to gender and sexuality. The misperception that all PLHA have the same needs, regardless of gender or sexual orientation, may lead to one-size-fits-all designs for service provision that do not adequately serve women or MSM. Informants in Ecuador and India also cited the homophobic attitudes of some NGO staff, which prevent MSM from being involved and/or coming out as homosexual/bisexual men when they are involved.

\section{Greater PLHA involvement requires creating a supportive NGO environment.}

The researchers found that lack of adequate financial and material resources for remuneration of PLHA is a serious problem for NGOs in all four countries. But many NGOs also need to examine their own operations, policies, and attitudes if they want to increase PLHA involvement. Specific barriers include:

- Judgmental and paternalistic attitudes about PLHA and their involvement by professional health and social workers.

At this point of time, I don't think that we will employ any positive person for childcare services.

NGO service provider, India

\section{Forming and Sustaining Support Groups}

Support or self-help groups are an important component of psychological support to PLHA because they provide a non-discriminatory environment in which PLHA can share experiences and information. To enhance their sustainability, NGOs should:

- Help members develop common objectives and expectations.

- Focus on involving participants in a similar geographical area, thus avoiding unsustainable transportation costs.

- Clarify the roles and responsibilities of support group members and the NGO, including the decision-making process.

- Develop mechanisms to cope with the death of members.

- Include opportunities for skills building. 
When we have a meeting and mothers come with their children I realize the importance of having a place for children to play....and have fun, so their mothers can relax.

HIV-positive service provider, Dios, Vida y Esperanza, Ecuador

The study identified five categories of institutional factors that contribute to building a supportive environment for PLHA involvement: nondiscriminatory staff attitudes, policies, and procedures; capacity building; psychological support; material support; and networking. These are further addressed in the recommendations section.

\section{Conclusions and Recommendations}

Findings from this four-country study show that there are many ways for PLHA to take part in the activities of NGOs and that the four types of involvement-access, inclusion, participation, and greater involvement-embrace a wide range of roles. However, the most common types of involvement observed in the NGOs that participated in the study were access and inclusion. Most PLHA involved in service delivery were volunteers, often working on an informal basis, and relatively few were employed as professionals by NGOs. Nevertheless, an important finding of the study is that all types of involvement can make a difference and that meaningful PLHA involvement should not be equated with public visibility and disclosure.

The study also highlights the fact that PLHA involvement in NGO activities is an organizational process and if key steps are not taken, the positive effects tend to be limited and negative effects can increase. For example, if PLHA are involved in outreach education without receiving the necessary training and support, this can adversely affect the quality of the service and can be harmful for the PLHA themselves.

NGOs can overcome many of the factors that limit involvement by implementing the following recommendations:

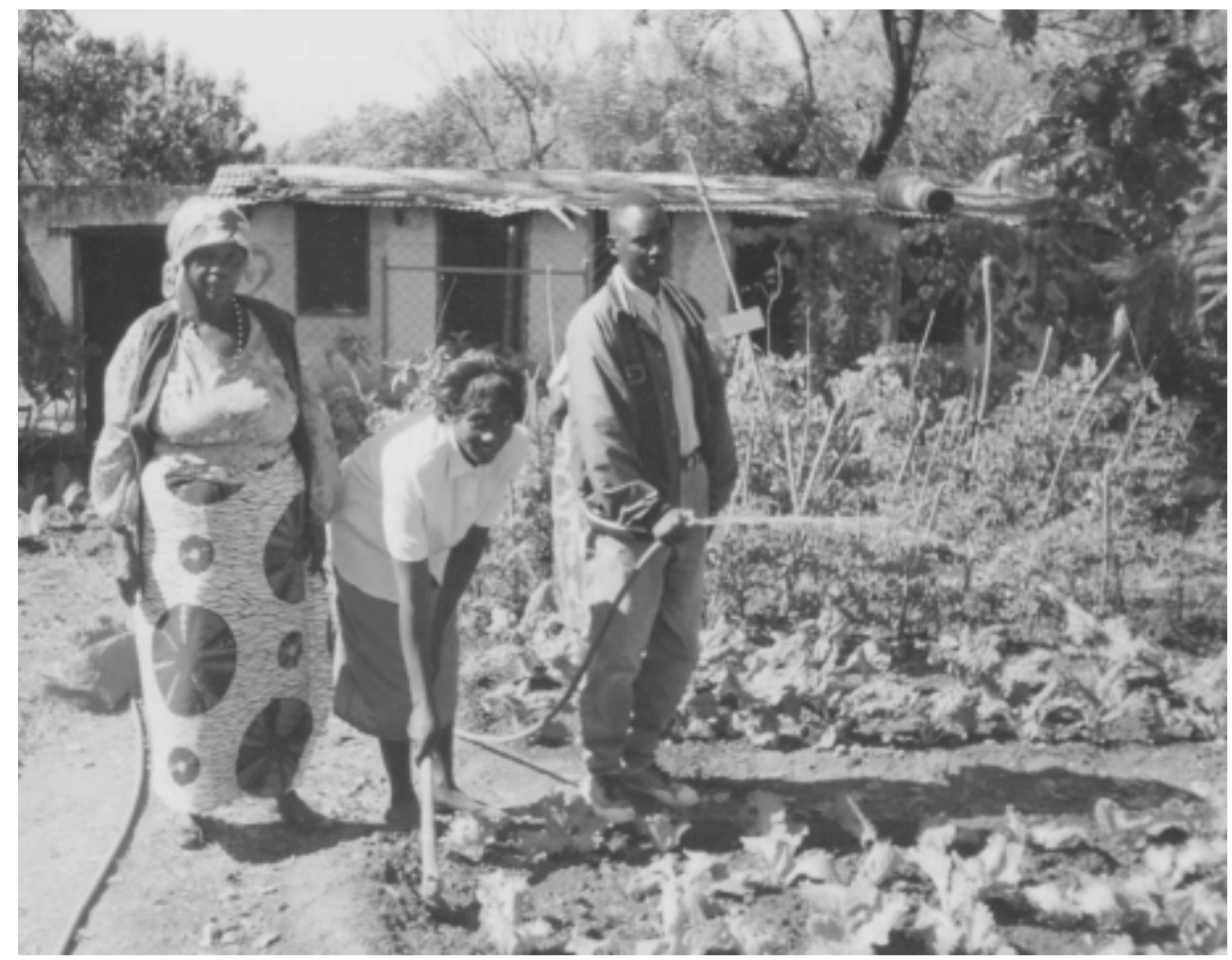

The Positive Living Advocacy Course of Hope Humana: PLHA learn gardening with an HIV-positive teacher. 


\section{Promote positive and non- discriminatory attitudes and policies toward PLHA.}

- Assess the attitudes of management and service providers and provide them with sensitization training where necessary.

- Review policies and procedures and overhaul those that stigmatize or discriminate against PLHA, including women and MSM.

- Ensure the confidentiality of all PLHA, both staff and clients.

- Allow PLHA to make decisions about their own disclosure and visibility.

\section{Build the capacity of PLHA for involvement.}

- Provide accurate information about prevention and treatment of HIVAIDS, as well as about services available to PLHA within the organization and from other sources.

- Use counseling services as a starting point for empowering beneficiaries.

- Orient PLHA to opportunities for involvement within the organization.

- Ensure that PLHA receive free or affordable training relevant to their activities like any other staff member or volunteer.

- Plan individual follow-up to training to ensure that benefits are not short term.

\section{Offer psychological support, including peer support, to PLHA.}

- Ensure that care and support provided by "professional" service providers is high quality and complemented by peer support.

- Provide PLHA beneficiaries with the opportunity to meet other PLHA, either through peer counseling or support group

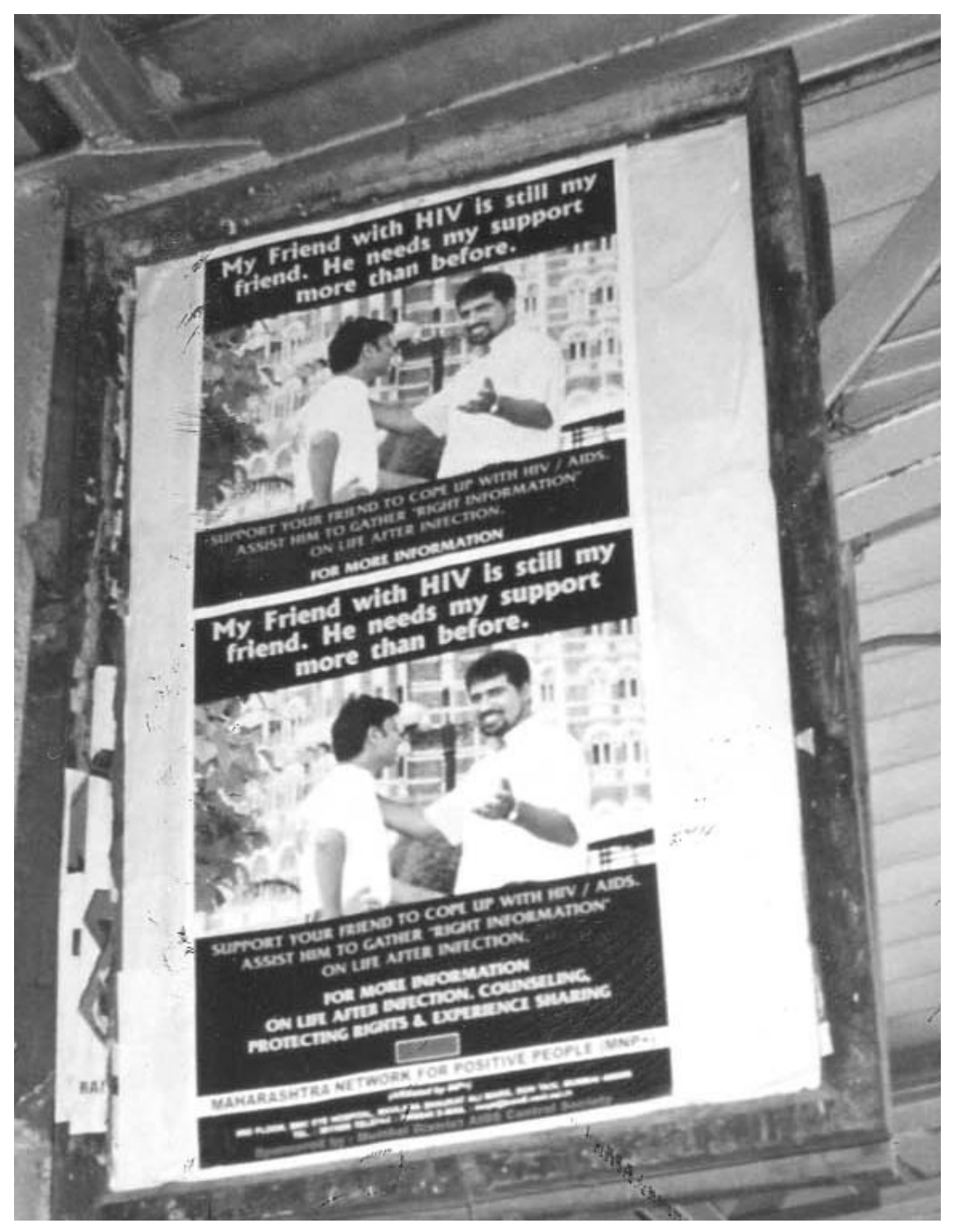

"My friend with HIV is still my friend" (poster developed by MNP+and displayed at a train station in India). meetings, taking into account gender and sexual orientation.

- Counsel PLHA and their families prior to giving public testimony or becoming more widely visible.

- Develop counseling strategies to help PLHA cope with perceived and actual experiences of stigma and discrimination. 


\section{Network with other organizations and services to foster PLHA involvement.}

- Encourage public and private sector HIV testing services to offer information to PLHA about NGO services and to refer PLHA to NGOs as quickly as possible.

- Diversify activities and choose communication strategies carefully to avoid identification as solely a "PLHA organization."

- Work with other groups to reduce stigma and discrimination at the community level by promoting tolerance and compassion, improving community knowledge and awareness about HIV/AIDS, sensitizing community and religious leaders, and advocating for the legal and human rights of PLHA.

\section{Provide material support to PLHA with few resources.}

- Provide remuneration depending on the amount of time spent on activities and skills used. This could include financial compensation, food, drugs, medical care, travel reimbursement, or childcare.

- Ensure that PLHA have free or low cost access to health care, including treatment for opportunistic infections, by offering health insurance, access to the NGO's own care facilities, or referral to other organizations or public services.

The study investigators are:

United Kingdom-International HIV/AIDS Alliance: Christophe Cornu (international study coordinator and principal investigator); Pam Decho (project support officer); Kathy Attawell (consultant editor)

Burkina Faso: Alfred Ouédraogo (research coordinator); Gisèle Kaboré, Augustin Sankara, Soungalo Traoré (research assistants)

Ecuador: Doris Herrera and Norma Velasco (research officers); Alejandrina Maldonado (research assistant)

India: Rajiv Dua (research coordinator); Vimla V. Nadkarni (principal investigator/technical advisor for India); Bindiya Nimla (research officer); Vaishali Sharma Mahendra (Horizons/India study coordinator) at the regional Horizons/ Population Council office in Delhi; Ujwala Bapat, Suchitra Inamdar, Neha Sachdev (research assistants)

Zambia: Tashisho Chabala (research officer); James Sulwe (data collection coordinator); David Mwanza, Justina Namukombo, Eric Shimumbwe, Agatha Zulu Wachinga (research assistants)

United States-Horizons: Christopher Castle (Horizons study coordinator)

The project team would like to thank the staff members, volunteers and service users of the 17 NGOs who participated in the study, INP+, NZP+; the staff of IPC (Burkina Faso), Kimirina and CEPAR (Ecuador), the Population Council offices in Burkina Faso and Zambia, and USAID missions.

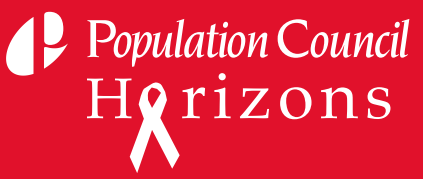

Population Council/Horizons

4301 Connecticut Avenue, NW

Suite 280

Washington, DC 20008

horizons@pcdc.org

www.popcouncil.org/horizons

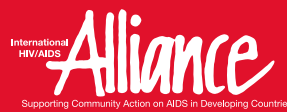

International HIV/AIDS Alliance Queensbury House 104-109 Queens Road Brighton, UK BN1 3XF mail@aidsalliance.org www.aidsalliance.org
UsAiD This publication was made possible through support provided by the Global Bureau of Health/HIV-AIDS, U.S. Agency for International Development, under the terms of Award No. HRN-A-00-97-00012-00. The opinions expressed herein are those of the authors and do not necessarily reflect the views of the U.S. Agency for International Development.

๑ 2002 The Population Council Inc. 


\section{Assessing Progress to Foster Greater PLHA INVOLVEMENT IN BURKINA FASO}

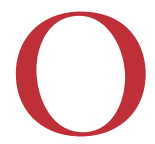

ne year after the completion of the diagnostic study assessing PLHA involvement in NGO service delivery in Burkina Faso, research was conducted to determine the study's impact on the five participating NGOs and on national policy. Researchers interviewed NGO staff, service users, and their families to determine the extent to which the NGOs implemented the strategies that they had proposed, and examined the impact on national policy development.

\section{Key Findings}

NGOs have initiated a variety of activities to reduce stigma within their organizations.

NGOs updated information provided during preand post-test counseling, sensitized members to change negative perceptions of PLHA, and encouraged members to get tested. Four of the five NGOs established support groups for PLHA and their families; one has a social group that provides meals for PLHA. These activities have helped PLHA accept their status, achieve a sense of solidarity, and share experiences without risk. However, NGOs say they have been unable to reduce fear of external stigma among PLHA. Despite training to participate in public community information meetings, PLHA prefer to engage in individual counseling.

"You can imagine that people infected and non-infected eating together out of the same bowl, it's really positive." PLHA

Training opportunities increased, but lack of compensation for PLHA remains a barrier.

All of the NGOs implemented new training for staff and volunteers, including pre- and post-test
HIV counseling, home visits, psychosocial counseling, advocacy, and care and support. Because PLHA volunteers' time is limited by other responsibilities, they prefer short training sessions or for training to be scheduled during their work hours, with the NGO negotiating for time off with their employers without compromising the confidentiality of their HIV status. Reliance on volunteers challenges both individuals, who find it difficult to work without remuneration, and the organizations, which experience interruptions in care.

Through networks and partnerships, NGOs have expanded access to some services.

Lack of funding and reduced availability of test kits impeded NGOs wishing to establish new testing centers, although some who were not already doing so established partnerships with local health care providers to expand access to voluntary counseling and testing, and care and support services. This involved negotiating agreements with public and private testing facilities to reduce fees in return for providing counseling. Two NGOs now collaborate with doctors to provide care and support services, and one NGO has established a referral system for PLHA. However, there has been no further expansion in access to treatment as a result of developing partnerships with local hospitals.

\section{NGOs have begun to publicize their activities, but further progress is needed.}

All the NGOs have made efforts to publicize their organizations and opportunities for involvement by disseminating brochures. One organization was featured on a radio and TV show, but other strategies targeted to key 


\section{National-level impact}

After completion of the diagnostic study, NGOs attended national HIV/AIDS strategy development meetings where they were able to provide the National AIDS Program and UNAIDS with the only source of data on PLHA needs in Burkina Faso. Study results stimulated the revision of the national HIV/AIDS strategy to include PLHA care and support needs.

constituencies proposed, including open-house days and PLHA group discussion sessions, were not implemented.

"I am a member, I'm not active, I only participate in the support group meetings. Otherwise I am not informed that I could develop or participate in other activities of the association." PLHA support group member

\section{Limited progress was made to involve PLHA in management and decision making.}

While all NGOs sought to increase the involvement of PLHA in decision making, few PLHA are aware that they can become involved in the organizations' managerial structures. Informants identified as obstacles the NGOs' hierarchical structure and the lack of clarity regarding the options for PLHA involvement beyond using services.

\section{Women's involvement increased despite the burden of household responsibilities.}

Although women head up three of the NGOs in the study, the involvement of women in NGO services generally has been limited. As a result of the diagnostic study, women have become involved in running some NGO activities, including information kiosks and a drug dispensary. Some women-only activities have been initiated, including a support group and an income-generating project. One NGO now refers women to legal services for property succession problems resulting from AIDS-related divorce.

\section{Conclusions}

The diagnostic study's participatory research process enabled NGO staff and members to consider, often for the first time, how to bring about change within their organizations and improve service delivery by involving PLHA. The follow-up study found that NGOs were more likely to implement PLHA involvement strategies that require internal organizational changes and few resources, but that they were overly ambitious regarding changes that require external inputs.

Nevertheless, the study shows that NGOs can undertake several important steps to foster greater involvement of PLHA, including women. These recommendations for expanding PLHA involvement emerged from the study:

- Develop realistic strategic plans with clear priorities for improvements.

- Improve staff capacity, including PLHA and volunteers, to create opportunities and a supportive environment for PLHA involvement.

- Network with other NGOs and care and support facilities to increase PLHA access to services.

July 2002

Study investigators for this study are Lisanne Brown, Horizons/Tulane University; Augustin Sankara, Gisèle Kabore, Idrissa Ouedraogo, Lydia Tapsoba, independent consultants; Joshua Volle, Tulane University.

Population Council Hprizons

Population Council/Horizons

4301 Connecticut Avenue, NW

Suite 280

Washington, DC 20008

horizons@pcdc.org

www.popcouncil.org/horizons

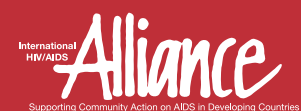

International HIV/AIDS Alliance

Queensbury House

104-109 Queens Road

Brighton, UK BN1 3XF mail@aidsalliance.org www.aidsalliance.org
Horizons conducts global operations research to improve HIV/AIDS prevention, care, and support programs. Horizons is implemented by the Population Council in partnership with the International Center for Research on Women (ICRW), the Program for Appropriate Technology in Health (PATH), the International HIV/AIDS Alliance, Tulane University, Family Health International, and Johns Hopkins University.
USAII

खर्ड

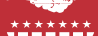

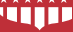

This publication was made possible through support provided by the Global Bureau of Health/HIV-AIDS, U.S. Agency for International Development, under the terms of Award No. HRN-A-00-97-00012-00. The opinions expressed herein are those of the authors and do not necessarily reflect the views of the U.S. Agency for International Development. 